\title{
LA HERRAMIENTA DIDÁCTICA DEL CINE EN EL APRENDIZAJE DEL DERECHO DE DAÑOS EN EL GRADO EN ADMINISTRACIÓN Y DIRECCIÓN DE EMPRESAS
}

\section{THE DIDACTIC TOOL OF CINEMA IN THE LEARNING OF TORT LAW IN BUSINESS ADMINISTRATION AND MANAGEMENT}

María Dolores Casas Planes (Universidad de Jaén) ${ }^{1}$

\section{Resumen:}

El trabajo expone una experiencia de innovación docente dirigida al alumnado de Administración y Dirección de Empresas: la enseñanza a través del cine de una materia específica de la asignatura de 'Introducción al Derecho'; en concreto, explicar la responsabilidad civil del empresario, de gran alcance práctico, a través de la visualización, comentario y análisis sistemático de unas películas, basadas todas en hechos reales. En orden a constatar dicho objetivo, en una primera parte se justifica desde un plano académico la utilización del cine como herramienta didáctica en las aulas universitarias, dando paso en una segunda parte a exponer la aplicación de dicho recurso docente, tanto sus objetivos como los resultados obtenidos sobre la base de la exposición y datos de los propios alumnos. En definitiva, el trabajo concluye de modo sucinto acerca de las bondades y también dificultades o vicios de la misma, pudiendo afirmar con certeza que la misma está en la línea de los planteamientos docentes que emanan de las directrices europeas diseñadas en Bolonia, al ayudar al alumnado cuya vocación no es jurídica, a captar de manera más global y profunda el sentido y finalidad de la normativa jurídica.

Palabras clave: derecho, responsabilidad civil, cine, innovación docente.

Códigos JEL: A-22, I-23.

Abstract:

The work presents an experience of teaching innovation aimed at students of Business Administration and Management: the teaching through cinema of a specific matter of the subject of 'Introduction to Law'; specifically, to explain the civil liability of the entrepreneur, of great practical scope, through the visualization, commentary and systematic analysis of some films, all based on real facts. In order to confirm this objective, in the first part it is justified the use of cinema as a didactic tool in the university classrooms from an academic point of view, giving way in the second part to expose the application of this teaching resource, both its objectives and the results obtained on the basis of the exposure and data of the students themselves. In short, the work concludes briefly about the benefits and als difficulties or vices of it, being able to affirm with certainty that it is in line with the teaching approaches that emanate from the European directives designed in Bologna, helping the

\footnotetext{
1 mdcasas@ujaen.es, Universidad de Jaén.

Recibido 5 de septiembre de 2019. Aceptado 28 de noviembre de 2019.
} 
student whose vocation is not legal, to capture in a more global and profound way the meaning and purpose of the legal regulations.

Key-words: Law, civil liability, cinema, teaching innovation.

JEL: A-22, I-23.

\section{INTRODUCCIÓN}

El aforismo jurídico latino "Ubi homo, ibi societas; ubi societas, ibi ius” -dónde hay hombre, allí hay sociedad; donde hay sociedad, allí hay derecho- seguro que resuena en el alumnado de cualquier asignatura jurídica. Y es que el Derecho está en todas partes, e, incluso, nos acompaña en el cine, como lo demuestra el que el Derecho ocupe un lugar relevante en el llamado Cine jurídico, y esto tanto desde el ámbito académico, como desde foros de cinéfilos (Pérez Montoro, 2017).

El objetivo del trabajo, al hilo de la afirmación anterior, se basa en exponer una experiencia de innovación docente: la enseñanza a través del cine de una parte del temario de la asignatura de 'Introducción al Derecho' al alumnado de primer curso del Grado en Administración y Dirección de Empresas (ADE). Esto es, ilustrar y explicar, a través de la visualización, comentario y análisis sistemático de unas películas, basadas todas en hechos reales, la 'responsabilidad civil extracontractual', sobre todo del empresario, que forma parte de la parcela más amplia del Derecho de daños perteneciente al Derecho privado patrimonial obligacional.

Este recurso didáctico se ha implementado en la docencia en Derecho con cierto éxito en la última década, a partir del año 2000, según la literatura jurídica y experiencias de técnicas de aprendizaje existentes para el Derecho español. Según el estudio de Rivaya, citado por Álvarez González (2015, p. 97) “(...) pues aunque con anterioridad ya se habían realizado algunas experiencias jurídico cinematográficas (cursos de Derecho y Cine en alguna Universidad privada, o la publicación en 1996 del libro Abogados de cine. Leyes y juicios en la pantalla, en 1996), no es hasta ese año cuando se implantan asignaturas de Derecho y Cine en las Universidades de Oviedo, Valencia y Autónoma de Barcelona. También es, casualmente, el año en que aparece un número de la revista Nosferatu que lleva por título Cine y Derecho. A partir de entonces, y sobre todo en los últimos años se han ido implantado bastantes asignaturas de Derecho y Cine en las Facultades de Derecho españolas”.

Es por ello, que la novedad que aporta este trabajo se basa en dos factores: por un lado, desde el punto de vista subjetivo, al estudiar la aplicación docente para una asignatura jurídica dirigida a un alumnado de Administración y Dirección de Empresas, con la dificultad que conlleva el hecho de que el perfil del alumnado no sea jurista, y que, además, provengan de nacionalidades diversas al cursar la asignatura de Introduction to Law en el Grado en inglés Bachelor's degree in Business Administration and Management. Y, por otro, desde el punto de vista del objeto, dado que de la revisión de la literatura científica se desprende que, existiendo cierto material de prácticas o de aprendizaje (Orozco González, 2018), se adolece de la falta de artículos o estudios que expongan la experiencia y los resultados de la aplicación del cine al estudio de una parcela concreta del Derecho patrimonial, como es el Derecho de daños; la cual, por otra parte es idónea al estar ante una materia eminentemente práctica, tal y como se argumentará más adelante. 
En definitiva, esta herramienta se podría subsumir en la más amplia denominada 'Problem based learning' o aprendizaje basado en problemas (ABP) del mundo anglosajón (Abel Souto, 2013, pp. 20-21). Este autor de modo coherente nos explica que, sobre la base de que el sistema de créditos europeos (ECTS) valora el volumen de trabajo total del alumno, expresado en horas, estamos ante un método educativo innovador centrado en el estudiante que promueve el trabajo interpersonal-colaborativo ${ }^{2}$. Y la misma es respuesta, como es sabido, a la demanda de la convergencia europea que radica en desplazar el punto de apoyo de la docencia desde la enseñanza al aprendizaje, giro copernicano en el que el alumno se sitúa en el centro ${ }^{3}$. En este sentido, Pérez Vallejo afirma que el proceso de convergencia hacia el EEES nos conduce al desarrollo e implementación de estrategias y retos formativos innovadores en la docencia universitaria; y que las líneas orientadoras del nuevo modelo deben responder a las competencias conceptuales (saber), procedimentales (saber hacer) y actitudinales (saber ser y estar) que definen el perfil del futuro egresado. Esto es, el Saber y Saber hacer necesario para abordar los problemas propios del ejercicio profesional (destrezas, competencias y conocimientos interdisciplinares); y Saber estar (valores de la profesión). En definitiva, para que el alumnado sea el protagonista de su proceso de enseñanza-aprendizaje, no basta ya que domine una serie de conocimientos, sino que tiene que saberlos integrar en sus futuras profesiones, generalizarlos y adaptarlos a las demandas de la sociedad (Pérez Vallejo, 2018).

\section{ANTECEDENTES DEL CINE COMO INSTRUMENTO PARA LA ENSEÑANZA DEL DERECHO, EN ESPECIAL PARA EL DERECHO DE DAÑOS}

Desde un plano general, tal y como se ha expuesto, en el mundo universitario cada vez más se predica que el cine puede contribuir en nuestro contexto actual a la enseñanza del Derecho, dado que estamos ante una realidad amplia y en continua y compleja relación con otras dimensiones (sociales, éticas, políticas, etc.,); a pesar de que históricamente haya predominado otra forma de entender el Derecho, aislando, en definitiva, su estudio de la sociedad en la que se aplicaba.

Es de señalar, en lo que respecta a iniciativas académicas europeas, la contribución a esta materia del grupo de investigación de Edimburgo que coordina el profesor Robsen, cuya obra más conocida es Film and the Law: the cinema of justice; así como las webs consagradas a dicha temática como Droit et Cinema: www.droit-justicecinema.fr (De Lucas Martín, 2013, p.6). Y respecto a la doctrina española pionera en este campo destacar, entre otros, a Pérez Triviño (2007); Gómez García (2009), y más recientemente a Rivaya García (2012); De Lucas Martín (2014) y Ruíz Sanz /2014) quién de modo acertado se cuestiona desde un punto de vista filosófico sobre la conveniencia de enseñar derecho a través del cine. Si bien, habría que matizar que esta técnica se ha desarrollado de modo más profundo en el campo del Derecho penal, tal y como lo ponen de manifiesto García Amado (2005) y Ríos Corbacho (2012); e incluso en enseñanzas trasversales al mismo como lo ilustra el interesante

\footnotetext{
2 “(...) la ABP surgió a finales de los sesenta para la materia médica y pronto se expande al resto de disciplinas entre las que se encuentran las Ciencias Jurídicas. El objetivo del método es que el "alumno aprenda a aprender", en los tiempos en los que la legislación cambia cada día, aprenda a trabajar en equipos. El ABP, son breves textos con problemas de la vida profesional que deben resolver y analizar en grupo; el problema estimula el aprendizaje, se basa tanto en la teoría constructivista (aprendizaje en colaboración con otros) como en la psicología cognitiva, promoviendo la motivación del alumno y el pensamiento crítico”.

${ }^{3}$ Es interesante como el autor nos recuerda que dicho axioma estaba ya presente en ideas ya señaladas a finales del siglo XIX o primeros del siglo XX por Giner de los Ríos, Macías Picavea u Ortega y Gasset, a cuyo juicio, en la construcción de la universidad hay que partir del estudiante, no del saber del profesor.
} 
estudio de Holgado Saéz (2013), acerca del programa de eugenesia y sus consecuencias. Lo dicho no obsta para que dicha herramienta se esté aplicando en otras ramas como el Derecho administrativo (Álvarez González, 2015); el procesal (López Picó, 2019), el constitucional (Salazar Benítez, 2015); y en la rama del Derecho civil, cuyo estudio es objeto de este artículo existiendo experiencias sobre todo en la docencia del Derecho civil de Familia (Pérez Vallejo, 2013, pp.15-16) ${ }^{4}$.

A mayor abundamiento, "el cine puede contribuir a mostrar esas diversas aristas de las que se compone el Derecho, así como sus múltiples y variadas conexiones con esos otros ámbitos con los que interactúa: la sociedad, la política, la moral, etc. Esto es lo que podría denominarse potencialidad contextual del cine (...)” (Pérez Triviño, 2007, p. 2). En esta línea de pensamiento, el Derecho no es solo el estudio en abstracto del significado de las normas jurídicas, va más allá, poniendo en cuestión la vocación del estudiante como abogado, como jurista, como juez, como empresario, y también como individuo o como parte de una familia que puede sufrir un daño, pues en las películas los protagonistas se enfrentan a dilemas que ponen en tensión y al límite sus propias convicciones. En palabras del mismo autor, "la formación en las facultades de Derecho debe ser interdisciplinar y a la vez debe tomar en consideración otros aspectos de naturaleza práctica y emocional. Si se acepta este presupuesto, también el cine puede constituirse en una herramienta docente fructífera dada su capacidad para lograr que el estudiante capte, comprenda y evalúe las consecuencias prácticas que implica la aplicación del Derecho (...). Esto es lo que podría denominarse potencialidad emocional del cine" 5 .

En otro orden de cosas, esta dinámica, asimismo, ayuda al estudiante a presentar modelos ético-jurídicos, político-jurídicos, y tener una visión más globalizada, al tener que realizar comparativas de sociedades y normas, pues es cierto que en sistema anglosajón el nivel de litigiosidad es más marcado, así como los operadores jurídicos ejercitan de un modo más evidente que el continental aspectos como la argumentación, la convicción o la persuasión, la oratoria y asertividad, los cuales son objeto también de aprendizaje crítico por el alumno (Ruíz Sanz, 2010).

Otras tesis sustentan que los estudiantes viendo, por ejemplo, una película pueden darse cuenta o analizar aspectos que no se verían dentro de un aula, en una clase teórica o

\footnotetext{
${ }^{4}$ Este autor afirma que el cine se presenta como un indiscutible vehículo para narrar el fenómeno jurídico que envuelve el desamparo y la protección de menores. Se ha dicho que el Derecho Privado aparece en el cine tanto o más que el Público, precisamente por estar implicado en las situaciones más cotidianas de la vida (Rivaya y De Cima, 2004). Este recurso de aprendizaje permite comprender aspectos relacionados con el contenido de las asignaturas, reflexionar sobre la problemática planteada en el caso y fomentar la discusión/debate constructivo entre los alumnos. El profesor juega ahora el papel de orientador, moderador y mediador. En definitiva, la utilización del Cine como recurso de aprendizaje es útil para promover el conocimiento y reflexión acerca de la problemática que, en líneas generales, plantea el acogimiento y la adopción de menores. Proporciona información significativa y el acercamiento a una realidad social muy presente en nuestros días sobre la que el alumno debe saber captar los problemas o conflictos que plantea la película.

5 “(...) que tuvo como consecuencia el dominio en los planes docentes de las facultades de Derecho de asignaturas que describían las distintas ramas del Ordenamiento Jurídico desde una perspectiva descriptiva y formalista. Trataban de ofrecer una imagen lo más neutral y aséptica de las normas jurídicas de un determinado ámbito (civil, penal, laboral, mercantil, etc.). Esta descripción solía hacerse de manera aislada, esto es, sin conectar las normas e instituciones jurídicas con la sociedad donde se desarrollaban. También había un distanciamiento respecto de los valores que las normas trataban de realizar o con el contexto político donde se aplicaban. Esta forma de describir el Derecho era propia de lo que se denominó formalismo, pero con algunas variantes, también fue sostenida por otras concepciones como por ejemplo, la de Hans Kelsen y su teoría pura del Derecho en la que el estudio del Derecho no puede estar contaminado por la sociología ni por la ética. Otro de los rasgos de esta tradición era la presuposición del Derecho como un conjunto de reglas racional, preciso y coherente que, una vez identificado y aplicado, suministraría la respuesta a los distintos problemas jurídicos”.
} 
realizando un caso práctico tradicional, donde han de detectar el conflicto jurídico subyacente y aplicar la norma correspondiente. El cine puede hacer que el estudiante pueda ser consciente de lo que implica tomar una decisión u otra. Por ejemplo, si bien para resolver un caso práctico donde un matrimonio con dos hijos quiere divorciarse se habrían de aplicar los artículos 90 y siguientes del Código Civil, nos hemos de cuestionar qué comporta para uno de los progenitores que se le otorgue la guarda y custodia al otro y no opte el juez por la custodia compartida. Y para ello se podría recurrir a la película Kramer contra Kramer, aunque el supuesto de hecho no sea el mismo, dado que es una forma de que los estudiantes puedan ver los intereses que hay en conflicto y cuáles pueden ser las repercusiones de tomar una decisión u otra (Cordero Cutillas et al., 2014). En este sentido, en palabras de Pérez Triviño los juristas no 'deberían ser meros autómatas' a la hora de aplicar las normas, ya que las mismas como sigue señalando el autor se enmarcan dentro de un contexto político, social, etc., y su aplicación a los casos concretos tiene importantes repercusiones en la vida de los individuos (Pérez Triviño, 2010).

En definitiva, según el experto Rivaya García (2006), el cine contribuye al aprendizaje del Derecho dado que: i) Es una innovación educativa que hace atractivos algunos contenidos. ii) Se centra en el aprendizaje del estudiante, lo que puede hacer que mejore el mismo. iii) Mejora la calidad de la enseñanza. Y, iv) Ayuda a ver las relaciones interdisciplinares entre materias, como el Derecho, la política, la moral, la religión. v) Ayuda a la formación permanente.

Por último, y concretando la experiencia llevada a cabo con el alumnado en la parcela del Derecho concreta del Derecho de Daños, la pertinencia de la herramienta didáctica del cine se basa en dos premisas: por un lado, en el hecho constatado de que el 'Derecho de daños y los litigios en los que se causa un daño ilícito con culpa o sin ella, sin necesidad de tener una vinculación contractual entre las partes, tiene cada vez más protagonismo en nuestros Tribunales y litigios, tanto en el sistema codificado como en el Common Law o derecho anglosajón; lo cual es una ventaja pues la temática de las películas americanas o europeas a visualizar tienen su trasunto en la realidad española, sobre todo en lo que concierne a la responsabilidad civil medioambiental, o por daños al consumidor por un empresario; sin olvidar los daños médicos. Es cierto que en el planteamiento y desarrollo de la actividad es necesario tener en cuenta que los sistemas del common law son distintos en muchos aspectos al sistema continental o de civil law, al diferir no sólo en la propia estructuración del proceso sino, principalmente, en el sistema de fuentes y la preeminencia de la jurisprudencia; encontrando, por otra parte, elementos que influencian cada día más a nuestro Derecho, como es el caso de los daños punitivos, tal y como se refleja en la cinematografía y series procedentes de la industria norteamericana (Orozco González, 2018). Y, por otro, en que dicho recurso es idóneo para alumnos de Administración y Dirección de empresas, que sólo tienen una asignatura de contenido jurídico a lo largo del Grado que estudian, dado que las películas reflejan, en bastantes ocasiones, algunas de las diferentes parcelas jurídicas (de derecho público y de derecho privado, y dentro de estas últimas, el derecho de la persona, de la familia, patrimonial, e incluso sucesorias) que tienen relación con un problema que acontece en la realidad.

\section{EXPERIENCIA DE SU APLICACIÓN EN LA MATERIA DE DERECHO DE DAÑOS EN LA ASIGNATURA DE 'INTRODUCTION TO LAW' A ALUMNOS DE GRADO EN ADMINISTRACIÓN Y DIRECCIÓN DE EMPRESAS: OBJETIVOS Y METODOLOGÍA}

Sobre la base de los antecedentes expuestos hasta ahora, la línea de pensamiento nos lleva a plantear unos objetivos concretos, los cuales permiten abordar la metodología 
adecuada. En términos generales, se ha utilizado una metodología cualitativa e inductiva, al basarse en la recogida de datos y opiniones por parte del alumnado; aplicando de igual modo la interdisciplinaridad, y la conexión del Derecho con otras ciencias, así como con la realidad social. Y esto en orden a comprender mejor cómo experimenta el alumno que no tiene un perfil jurídico el aprendizaje de una materia jurídico-legal de trascendencia ético-social.

En este sentido, los diferentes objetivos se exponen a la vez que el instrumento escogido para llevarlo a cabo. En concreto, los fines en la aplicación de la herramienta del cine en el aprendizaje de la responsabilidad extracontractual, en particular en relación a los daños que un empresario pueda causar, son los siguientes:

i) Que el estudiante capte, comprenda y evalúe las consecuencias prácticas que implica la aplicación del Derecho del Derecho de daños, que se basa en el principio de justicia: 'quién causa un daño injusto ha de repararlo', positivizado entre otras normas, en los artículos del 1902 al 1910 del Código civil español; o en los artículos 147 y 148 del Real Decreto Legislativo 1/2007, de 16 de noviembre, por el que se aprueba el texto refundido de la Ley General para la Defensa de los consumidores y usuarios, y otras leyes complementarias; máxime en un mundo globalizado como el de hoy en día. Así como, por otra parte, indagar en dichas consecuencias desde un 'análisis interdisciplinar', pues tal y como se ha apuntado anteriormente un asunto civil puede tener repercusiones penales (Erin Brockovich, Acción civil) o un asunto penal permite analizar cuestiones de deontología profesional (Las dos caras de la verdad), o un problema jurídico da pie para analizar cuestiones morales (Senderos de gloria y Stico $)^{6}$, etc. Son numerosos los ejemplos de películas que ofrecen la oportunidad al profesor para llevar a cabo un análisis jurídico donde el Derecho es analizado en el contexto social o bien, donde los diversos problemas jurídicos pueden ser estudiados conjuntamente.

Para ello, en primer lugar, metodológicamente, el docente debe realizar una labor de selección de tres a siete películas clásicas y actuales (adecuadas por su contenido y puesta en escena), para ofrecer al alumno/ o grupo de alumnos con el fin de que escoja/n cuál/es analizar $^{7}$. Verbigracia, en la actividad desarrollada se escogieron tres películas relacionadas con los daños del empresario causados al medio ambiente y a los particulares; así como con los daños médicos y daños al consumidor: ‘Acción civil’ (USA) ${ }^{8}$, 'Erin Brockovich’ (USA),

\footnotetext{
6 Sucintamente, los datos filmográficos de las películas citadas (director, año y país) son: Erin Brockovich: Steven Soderbergh, 2000, Estados Unidos; Acción civil: Steven Zailllian, 1998, Estados Unidos; Las dos caras de la verdad: Gregory Hoblit, 1996, Estados Unidos; Senderos de Gloria: Stanley Kubrick, 1957, Estados Unidos; y Stico: Jaime de Armiñán, 1985, España.

7 Tener en cuenta como referente obligado para la selección de películas a Rivaya García al ser abogado, profesor de Filosofía del derecho, experto en cine jurídico y autor, entre otros trabajos, de Derecho y cine en 100 películas. Una guía básica. Ed.,Tirant lo Blanch, Valencia, 2004, pp. 12-29; y "Derecho y cine. Sobre las posibilidades del cine como instrumento para la didáctica jurídica”, Una introducción cinematográfica al derecho (coor. Rivaya García), Ed, Tirant lo Blanch, Valencia, 2006; y Un vademécum judicial. Cine para jueces. Ed. Tirant lo Blanch, Valencia, 2012. Tener en cuenta, de igual modo, a Ortega Giménez, A./ Pérez Tortosa, F./Pastor Válcárcel, M.C. (2013). Cine y Derecho en 21 películas. Materiales y recursos para el estudio del Derecho a través del Cine. Ed. Editorial Club Universitario, Alicante. Y, más en concreto para la materia de Derecho de Daños, Orozco González, M. (2018). "Nuevos horizontes del Derecho de daños: una visión cinematográfica.Materiales para la enseñanza del Derecho de Daños”, en https://digibug.ugr.es/handle/10481/53701.

${ }^{8}$ Para un resumen de la película de Acción civil, que resalta que el ejercicio de la abogacía conlleva una tarea importante, pero dura y muchas veces incomprendida, pues sobre los hombros de un abogado recae la tremenda responsabilidad de defender los intereses de su cliente, no los propios, para bien y para mal., vid. http://adancastaño.com/2015/04/28/el-ejercicio-de-la-abogacia-en-la-pelicula-accion-civil-contiene-spoilers-2/ $\quad$ y http://justiciahorizontal.blogspot.com/2009/07/un-accion-civil.html;. Brevemente, el conflicto jurídico se encuentra representado por el daño a la salud, a la vida y al medio ambiente sufrido por los habitantes de Woburn debido al consumo de agua contaminada. Dicha contaminación es consecuencia inmediata de la acción de las firmas ‘Beatrice’ y 'Grace’ al vertir residuos contaminantes al río.
} 
ambas sobre daños medioambientales y la más reciente y polémica titulada 'Contergan' (Alemania) por su relación con el polémico caso de la Talidomina o daños médicos ${ }^{9}{ }^{10}$.

De tal modo que estamos ante la oportunidad de que el alumno aplique la enseñanza adquirida a litigios medioambientales y médicos en España. Por ejemplo, por un lado, el caso llamado Erin Brockovich español resuelto por el Juzgado de Primera Instancia número 5 de Madrid en 2018 (en el que se condena a la empresa Uralita S.A. a abonar 1.7 millones de euros a un grupo de vecinos y familiares de las localidades de Ripollet y Cerdanyola, en concepto de indemnización por las patologías relacionadas con la exposición al amianto ${ }^{11}$ ), dado que, de modo parecido, en el caso americano la contaminación del agua de la localidad de Hinkley, California, provocaba enfermedades respiratorias, insuficiencia cardíaca y problemas reproductivos. La empresa responsable de la contaminación tuvo que pagar una indemnización de 333 millones de dólares. Y, por otro, la película Contergan tiene su parangón en la historia jurídica derivada del caso de la Talidomina en España, en concreto, la reclamación de indemnización de daños y perjuicios por las personas que nacieron con malformaciones como consecuencia de la ingesta de talidomina por sus madres en los primeros meses de gestación hace más de cincuenta años ${ }^{12}$.

En segundo lugar, en esta primera etapa es necesario que el profesor elabore una 'guía completa' acerca de cómo analizar una película (agente, ambiente fílmico, acción cinematográfica), complementada con bibliografía básica y enlaces de interés relacionados con el film. De este modo el alumno cuenta con una necesaria batería de información $(A A . V V, 2011)^{13}$.

ii) Que el estudiante tenga en cuenta los 'valores' que las normas tratan de realizar, y el contexto social en el que se aplican, pues los sentimientos, la moral, la ética forman parte del Derecho.

Y en atención a dicho objetivo, el profesor elabora una 'ficha-modelo' en la que se requiere al alumno que cumplimente unos datos concretos. En particular, en la ficha entregada se les solicitó al alumnado que cumplimentaran los siguientes datos, teniendo en cuenta que la actividad requiere de una mejora futura, mayor concreción y desarrollo tras el feed-back realizado con el alumnado:

a. Director y año de la película.

b. Resumen en dos o tres párrafos del argumento de la película.

c. Seleccionar por el alumnado tres momentos claves del film que sean relevantes para poder ser visualizados ante el resto de los compañeros (máximo 7 minutos).

d. Respecto a la relación de la película con la materia estudiada: la responsabilidad extracontractual del empresario, o del médico etc.,

- destacar por el estudiante tres enseñanzas que estime de valor y haya aprendido con su visualización, no sólo a nivel legal, sino también ético, y social, etc.,

\footnotetext{
${ }^{9}$ Director, año y país: Adolf Winkelmann\& Benedik Röskau, 2007, Alemania.

${ }^{10}$ Otras dos películas pertinentes para el Derecho de daños son citadas por Orozco González, Ibidem, p.4. Veredicto Final (The Verdict), Año 1982, Sydney Lumet; y Causa Justa (Rainmaker), Año 1997, Francis Ford Coppola.

11 Vid. LA FUENTE ABOGAdOs (2018). El caso Erin Brockovitch en español. https://lafuenteabogados.com/sincategorizar/el-caso-erin-brockovich-espanol/.

12 Un resumen del historial jurídico en España en Vaquero Pinto, 2017, pp. 275-316.

${ }^{13}$ Es un texto de referencia pues explica como debe acometerse el cometario de películas (sobre todo de cine jurídico), y el método a seguir (basado en el hecho cinematográfico y en el hecho fílmico).
} 
- señalar, desde el punto de vista comparativo, la/s diferencia/s o semejanza/s entre el derecho español y el derecho del que trata la película en lo que respecta a la responsabilidad civil extracontractual, en este caso, el derecho americano y germánico: por ejemplo, respecto al elemento de imputación como la culpa; la relación de causalidad; el daño; su prueba, etc.,

- realizar una conclusión crítica sobre el interés del ejercicio, su dificultad y la enseñanza principal.

e. Elaborar, al menos tres preguntas para discutir en clase con el resto de grupo y poder extraer conclusiones finales.

iii) En consecuencia, otro objetivo sería fomentar el ‘trabajo en ‘equipo' dado que la ficha citada anteriormente habría de ser consensuada en el grupo, así como las conclusiones del trabajo. En concreto, han de tratar de ordenar las ideas que les hayan surgido en torno al interés, dificultad, personaje con el que se identifican, conflictos jurídicos y éticos, etc.,. Por otra parte, el número máximo de alumnos sería tres, habiendo, sin embargo, permitido los trabajos individuales. Ahora bien, el número relativamente escaso de alumnos matriculados permitiría grupos de dos alumnos, e, incluso individuales, facilitando la evaluación oral más justa de cada uno de ellos. En este sentido se ha de matizar que la posibilidad de ofrecer la actividad de modo optativo y no obligatorio conlleva una autoselección del alumnado interesado, que luego puede implicar una participación no del todo pasiva de los alumnos que no la hayan llevado a cabo y oyentes en la exposición final.

iv) Por último, el desarrollo por el estudiante de la argumentación, asertividad y oratoria a través de la exposición oral por los diferentes grupos al resto de la clase (de los resultados de la ficha-modelo entregada) en dos horas, habiendo utilizado una hora de prácticas y otra de teoría para su mejor desarrollo. De modo alternativo, en el caso de estar ante un grupo bastante reducido de alumnos, voluntarios de la actividad, pudiera llevarse a cabo la actividad final (así como los encuentros previos de trabajo del alumnado voluntario), en lugar de en el aula asignada al grupo, en un 'Seminario', en concreto en el Seminario de Derecho civil como lugar físico ${ }^{14}$. Pues, como han puesto de relieve J. Pujol y Fons (1981, p.6): “el mismo hecho de que el Seminario exija un lugar especial llamado normalmente con ese nombre, en donde los alumnos, además de participar en las reuniones, pueden trabajar, consultar bibliografía, etc., hace más fácil que se forme una estrecha comunidad entre profesores y estudiantes comprometidos en un mismo trabajo". Sin olvidar que el resultado provechoso de un seminario está en relación inversa al número de sus componentes y en función directa de su nivel de preparación. La exposición final oral podría llevarse a cabo en horario de tutoría y con la invitación a los compañeros interesados, avisando por docencia virtual y en clase de la celebración del lugar y hora de dicho Seminario.

${ }^{14}$ Los Seminarios constituyen no sólo un complemento en la labor docente sino también una iniciación en la labor investigadora del alumnado. En el sistema de crédito europeo cobran una gran potencialidad. Los seminarios suponen la profundización en temas puntuales con evidente interés, conllevan el estudio de materias de carácter monográfico. A diferencia de las clases magistrales donde prima la intención de transmitir conocimientos a los alumnos, en los seminarios lo fundamental es la labor crítica y de interrogación sobre ciertos puntos. Por ello, las sesiones de seminario pueden constituir una buena forma de procurar el acercamiento entre profesor y alumno, así como una enseñanza más personalizada. Las ventajas de los seminarios son indudables para ambas partes, pero de manera especial para el alumno. A este no solo le brinda un conocimiento más profundo de la materia, sino que además lo inicia en la investigación científica, al tiempo que favorece el desarrollo en él del pensamiento crítico y original. Y está claro que, al propiciar la creación de estos hábitos, se convierte en uno de los mejores instrumentos para la posterior autoeducación e investigación autónoma. Por otra parte, no hay que olvidar que las sesiones de seminario incentivan la intervención oral de los alumnos, intervenciones que éstos no siempre se atreven a realizar en las más o menos multitudinarias lecciones ordinarias. Además, si el número de alumnos del seminario es el adecuado, se favorece el diálogo científico entre profesor y alumnos. 
En este punto es de interés resaltar que la exposición oral servirá para extraer finalmente conclusiones o conceptos generales entre el alumnado que participe en la actividad con la debida guía o coordinación del docente; sobre todo en la fase final en la que se platean preguntas a los compañeros que no han participado pero que son asistentes. En realidad, esta técnica de formulación de preguntas o método inductivo es de gran importancia y permite a los alumnos la resolución de problemas que se planten por medio de hábiles preguntas que iluminan el entendimiento ${ }^{15}$. En relación a este objetivo, es de interés destacar la reflexión de Pérez Triviño (2007, p.77) en torno a la tarea del profesor de guiar el debate y las eventuales emociones que se vayan provocando entre los estudiantes. El autor afirma que "para el correcto encauzamiento de las emociones es muy útil que los alumnos vean la película juntos y la discutan colectivamente. El hecho de ver una película y evaluarla conjuntamente en un aula con los compañeros y en presencia del profesor es interesante y útil dado que presupone que el alumno se ha introducido en la trama vital de la película y a la vez debe adoptar un papel distanciado y crítico respecto de ella, en esa medida se ve compelido a contrastar lo que ha visto y lo que ha experimentado con su propia experiencia vital, pero también con la de los compañeros (que probablemente será distinta). En este sentido, el alumno entrará en una confrontación que tiene mucho que ver con la propia argumentación jurídica, en tanto en cuanto tendrá que aportar ante sus compañeros razones que justifiquen su comprensión de la película o la interpretación que lleve a cabo de los problemas que allí aparezcan. Y sus compañeros harán, a su vez, otro tanto. En algún sentido, en la discusión se refleja algo característico del contraste de opiniones y de razonamientos que se dan en un debate jurídico”.

Respecto a esta última parte o fase de la actividad, por un lado, sería provechoso contar con la asistencia de prácticos del derecho invitados al debate, juristas o abogados especializados en el tema, así como con la de algún experto en cine, cuya colaboración se torna necesaria, y su interacción seguro que adecuada e enriquecedora. Y, por otro, sería sugestivo realizar unas Jornadas universitarias sobre dicha experiencia, para poner en común las nada desdeñables aplicaciones en este campo. Como proyecto de futuro, las conclusiones del trabajo podrían trasladarse a la sociedad, a través de la búsqueda de algún medio de comunicación, como por ejemplo, difundiendo sus resultados en algún programa de la radio universitaria; así, como la 'grabación' de la exposición de los grupos seleccionados en un vídeo que sería subido a la web. En concreto, a docencia virtual para la visualización por parte del alumnado; e incluso, se podría plantear subirlo a la página web del Departamento de derecho civil en el que se inserta la actividad, o en el blog jurídico del profesor, en su caso.

Finalmente, como toda actividad de innovación se requiere de un feed-back en el que se valoren, a través de un cuestionario anónimo individual, los aspectos positivos y negativos de la actividad en sí, así como su metodología, y experiencia en general.

\section{RESULTADOS DE LA ACTIVIDAD. VALORACIÓN POR PARTE DEL ALUMNADO}

En términos generales, la actividad se puede calificar de satisfactoria y enriquecedora para el alumnado, según su opinión, y altamente gratificante para el docente, dado que fue sorprendente el nivel de exigencia del alumnado, sobre todo respecto al item de la relación

\footnotetext{
${ }^{15}$ Es sugestivo aplicar en las aulas la mayéutica (socrática) como técnica que consiste en interrogar a una persona para hacerla llegar al conocimiento no conceptualizado. Se basa en la dialéctica, la cual supone la idea de que la verdad está oculta en la mente de cada ser humano. La técnica consiste en preguntar al interlocutor acerca de algo y luego se debate la respuesta dada por medio del establecimiento de conceptos generales.
} 
del derecho con los valores y la ética de una sociedad en concreto; identificándose la mayoría con alguno de los personajes, realizando exposiciones maduras y asertivas.

No obstante, la dificultad experimentada se debió a la falta de una explicación teóricopráctica más desarrollada de la parte general del Derecho de daños, y más en concreto de la responsabilidad extracontractual del empresario; al ser cierto que una base teórica facilita siempre un mayor aprovechamiento de este tipo de actividades. Pues, en realidad, el Derecho de Daños es una materia muy práctica, pero a la vez de media o alta complejidad, dado que sus presupuestos han sido elaborados en su mayor parte por la jurisprudencia del Tribunal Supremo, y por la jurisprudencia menor que vienen sosteniendo diversas teorías ante ciertas controversias; adoleciendo en ocasiones de la falta de consenso sobre la interpretación de la escasa normativa jurídica existente al respecto.

En concreto, la actividad se planteó como voluntaria, contando con once alumnos, y la realizaron todos de modo individual, sin poder constatarse el objetivo del trabajo en grupo. Es necesario concretar que la tarea de aprendizaje está conectada a una materia recogida en la guía docente, en concreto a un epígrafe de la lección quinta: La obligación (II), en la que el alumno tiene como finalidad indagar en la diferencia entre la responsabilidad contractual, también estudiada en dicha lección, y la responsabilidad extracontractual o civil. Más en concreto, dado el perfil del alumnado, se analiza y estudia la responsabilidad civil por hecho propio del empresario, así como por hecho ajeno de sus empleados, ya comentan estos últimos un ilícito penal o delito, como un ilícito civil. Por ello, no estamos ante materia trasversal del programa.

En consecuencia, la actividad fue evaluable en un doble sentido, por un lado, eliminaban dicho epígrafe de la materia de examen final (sólo un epígrafe del tema) aquellos alumnos que visualizaran, trabajaran, entregaran cumplimentada la ficha y la expusieran ante el resto de los compañeros en un debate final; y que finalmente superaran la actividad (al enfrentarse a preguntas y contra-preguntas a las que tuvieron que responder y demostrar las competencias descritas). Y, por otro lado, la valoración se tenía en cuenta en el 30 por cien de la nota final respecto al conocimiento práctico de la materia, tal y como indica la guía docente de la asignatura. En concreto se valora la riqueza de contenido con un 60 por cien, la claridad expositiva en un 15 por cien y el sentido crítico representa un 25 por cien. De tal modo que, dado el resultado positivo de la tarea expuesta sería coherente y pertinente insertar la actividad en el programa docente de la asignatura, tras su consenso por el área de Derecho civil. Es significativo tener en cuenta que en el 2019 el área de Derecho civil implicada ha presentado, tanto comunicación sobre la materia a un Congreso de Innovación docente y problemáticas en el ámbito jurídico en la Universidad de Santiago de Compostela (mayo 2019), y ha presentado en la misma línea un Proyecto de Innovación e Incentivación de las buenas prácticas docentes en la Universidad de Jaén (2019-2020), titulado: "El cine como herramienta ético-jurídica del aprendizaje del Derecho de Daños, y su aplicación al alumnado con necesidades especiales”. En definitiva, la evaluación descrita está en la línea de potenciar un modelo de evaluación más participativo e interactivo, al que conmina los planteamientos de Bolonia.

Y en relación con el item en el que se les preguntaba acerca del interés del ejercicio, su dificultad y el aprendizaje principal que han extraído, los resultados serían los siguientes:

i) Sobre la satisfacción de la actividad, su realización en orden al aprendizaje de la institución jurídica en estudio ha sido calificada en un 90 por cien como 'positiva', 'interesante', y 'entretenida' y que ayuda a comprender la materia al basarse todas las películas en hechos reales. En concreto, argumentan que 'estudiar la teoría es una cosa, y otra diferente aprehenderla a través de un ejemplo de la vida real. El material visual y especializado de los films facilitan la comprensión y la asimilación de la finalidad de una 
institución jurídica'; o 'ver una película y señalar los momentos más relevantes para nuestro aprendizaje es una interesante manera de estudiar esta materia'.

ii) Sobre la dificultad de la actividad de innovación, en términos generales, se ha calificado de dificultad media; especificando, por una parte el inconveniente de que las películas seleccionadas no entran en detalle sobre la norma aplicada al caso en concreto, argumentando que 'antes de ver la película sería interesante conocer más en profundidad sobre el derecho sustantivo y procesal sobre el que gira la película'. De tal modo que faltaría perfeccionar el material que se ha ofrecido al alumno al inicio de la actividad que comprendía, como se ha señalado, bibliografía y enlaces relativos a la temática del film.

Y, por otra, un 30 por cien del alumnado participante concretaron que la dificultad provenía, sobre todo, en encontrar ejemplos sobre el estudio comparativo entre el derecho español estudiado y el derecho americano expuesto en la película (pues de los once alumnos diez escogieron las películas americanas, y sólo una alumna de origen germánico escogió trabajar la película 'Contergan'). No obstante, es de interés destacar que la mayoría del alumnado extrajo la diferencia sobre la 'prueba del elemento de la culpa' o ‘criterio de imputación subjetivo', al constatar el estudiante que en el derecho americano, en general, la culpa del empresario debe ser probada de modo inequívoco y sin admitir la presunción de culpa en actividades de riesgo (empresarial en estos casos) ${ }^{16}$, tal y como, por el contrario, permite el derecho español. Así como la información relativa a la brevedad del plazo de prescripción de la acción de responsabilidad extracontractual en el derecho español y en el americano.

iii) Y por último, acerca del aprendizaje primordial de la actividad y de la película visionada, los alumnos en un porcentaje similar destacaron aprendizajes que en un 70 por cien parecían expuestos por alumnos de Derecho, lo que demuestra interés y la motivación en un trabajo.

En concreto, los aprendizajes destacados por el alumnado se pueden sintetizar en los siguientes:

a) la importancia de analizar un problema desde diferentes puntos de vista, y tener en cuenta las circunstancias del caso en concreto, sobre todo en materia de Derecho privado, esto es, la importancia de la 'equidad' en la aplicación del derecho. b) La utilidad del 'arbitraje' como mecanismo alternativo de resolución de conflictos en caso tan complejo como el expuesto en la película de Erin Brockovich. c) Entender de modo práctico y haber sabido identificar algunos de los presupuestos de la responsabilidad civil extracontractual, destacando: por un lado, el más complejo de la 'antijuridicidad' y las causas de justificación que conllevan la falta de dicho presupuesto, como el 'cumplimiento de un deber'. Tal y como se pone de manifiesto en los primeros minutos de la película de Erin Brockovich en la que la protagonista tiene un accidente de coche al ser arrollada por un médico que conducía de modo temerario en un supuesto cumplimiento del deber, de modo que se le exonera del deber de indemnizar por falta de antijuridicidad (a pesar de la falta de prueba sobre el mismo, dado que la película plantea otras cuestiones ético-sociales, como los prejuicios humanos). Y por otro, el de la 'relación de causalidad adecuada' y su posible ruptura, pues en la película de Acción civil los abogados de la empresa, al fracasar los intentos de conciliación, buscan romper el nexo de causalidad adecuada planteando que al no comprobarse que los residuos

\footnotetext{
${ }^{16}$ A excepción de la llamada 'strict liability' o responsabilidad objetiva o sin culpa por los daños derivados de por productos defectuosos, o por actividades de extremo peligro (hazardous activities), vid. "Product liability in the USA” (2018), en https://www.lexology.com/library/detail.aspx?g=3714f105-6d2e-4e33-be4f-17289ae7e547 (fecha de consulta 12/11/2019).
} 
volcados en los pozos llegaron hasta el río contaminando las aguas, no existe responsabilidad ni por tanto obligación indemnizatoria.

b) O el más importante aprendizaje sobre la 'finalidad de una institución jurídica', cual es en este caso la mera compensación, y no 'cesar la actividad'; cesación de la misma que persigue en muchas ocasiones la víctima del daño; tal y como se pone en evidencia en la película de 'Civil action'. En concreto, en las primeras escenas en las que se refleja que la parte actora pretende con su acción el resarcimiento por los daños a la salud, la vida, daño moral, daño psicológico injustamente padecidos por los pobladores de Woburn que han sufrido la muerte de seres queridos o enfermedades crónicas por la acción antijurídica culpable de dos empresas contaminantes. Pero asimismo matiza que lo más importante para la protagonista principal (madre de uno de los niños fallecidos) es el cese inmediato de la actividad contaminante y la recomposición del medio ambiente; y sobre todo 'una disculpa'. De tal modo que el alumno va a poder acometer una visión crítica de la institución jurídica, y plantearse interrogantes, lo cual es el fin de toda enseñanza.

\section{CONCLUSIONES}

En definitiva, el alumno a través de la aplicación correcta de este método con implicaciones de innovación docente (sobre la necesaria base de una buena selección de las películas, y una correcta explicación y guía del profesor) se acerca al estudio jurídico de modo más realista, interesante y amable. Tal y como señala la doctrina especializada, el alumnado en estos casos está más motivado para analizar una cuestión que cuando acomete dicho análisis a través de una actividad teórica, al no captar del todo en estas últimas su contexto, su relevancia o sus diversas consecuencias prácticas.

Es interesante como en la actividad, los alumnos se han planteado una diversidad de cuestiones con una madurez mayor de la esperada, sobre todo en cuestiones jurídicas que no son del interés prioritario de alumnos de Grado en Administración y Dirección de empresas. Entre otras, y por destacar las más relevantes: la búsqueda del bien mayor en un conflicto de intereses; la vocación de una profesión; la relación del Derecho con la sociedad, que se refleja en que los principios generales del derecho tienen su fuente en las convicciones esenciales de una sociedad y, por tanto, que personas, como la protagonista de una de las películas sin formación jurídica, pueden alcanzar por intuición el conocimiento de ciertas reglas sobre la negligencia o la trascendencia de la prueba. Por otra parte, señalan el haber aprehendido la debilidad de la posición de un consumidor ante los daños causados por un medicamento o producto dañoso, y la necesidad de una regulación específica al respecto; resaltando una alumna de origen germánico acerca del caso Contergan (película de 2007 sobre hechos acontecidos en los años 50 en Alemania) que: 'en el hecho de que en el 2012 la Compañía Chemie Grünewald construyera a las víctimas un monumento no hizo sentir a las víctimas mejor, cuando la compañía los silenció durante bastante tiempo con dinero, mientras los niños con dichas deformidades eran despreciados por la sociedad'.

Finalmente, lo que la mayoría de los alumnos destacaron es la importancia de la 'lucha por la verdad' a pesar de las dificultades que se puedan tener, como enfrentarse al poder de una gran compañía, pues arguyen de modo ilustrativo en sus comentarios 'si el derecho y la verdad están de tu parte eres invulnerable'; y sin embargo 'he aprendido que la información de interés público no llega a la gente, al revés la adquieren de forma deformada'.

Se estima que esa actividad puede contribuir en cierto modo a completar ciertas carencias de la formación de los universitarios; es cierto, de modo más palpable en la de los juristas. En la medida que la obra cinematográfica (al igual que la literaria) invita a los espectadores a ponerse en el lugar de personas muy diversas ( $\mathrm{y}$ a veces alejadas de su propia 
vivencia personal) y a adquirir empáticamente sus experiencias y sentimientos, el alumno está en mejor disposición para comprender mejor y más integralmente el impacto de un conflicto (o de una sentencia, o de una norma jurídica) en la vida de las personas. De esta forma puede captar de manera más global y profunda el sentido y finalidad de aquellas.

Este acercamiento, por otra parte, tal y como se viene apuntando, está en la línea de los planteamientos docentes que emanan de las directrices europeas diseñadas en Bolonia que, como es sabido en su aplicación al ámbito jurídico, insisten en la necesidad de transmitir contenidos teóricos, pero también, competencias y actitudes con las que los futuros juristas puedan enfrentarse con éxito a las distintas situaciones en que pueden encontrarse en su desarrollo personal (Pérez Triviño, 2007, p. 6). En palabras de Ruíz Sanz (2014, p. 6) “(...) El cine es un medio de comunicación excepcional, yo diría que exquisito. No cabe la menor duda de que ahora, con el Plan Bolonia, hay una oportunidad impagable de acercar el cine con sutileza al ámbito universitario. En nuestra mimética sociedad espectáculo no puede prescindirse de la función de entretener y por lo tanto el recurso al audiovisual, en todas sus posibles manifestaciones, supone un buen reclamo para ello".

No obstante, las virtudes apuntadas sobre la enseñanza del Derecho a través del cine, tampoco se deben ocultar sus inconvenientes. En esencia, es muy importante tener presente el diseño de la actividad a realizar, las competencias que se quieren trabajar o los resultados de aprendizaje a asimilar por los estudiantes. De ahí que como se ha puesto de manifiesto por parte de algún autor, es necesario seleccionar bien las películas que queremos utilizar en clase, y que los alumnos sean conscientes del tipo de película que están viendo (Cordero Cutillas y otros, 2014).

En definitiva, los alumnos son los destinatarios de los mensajes jurídicos y cinematográficos. Si se encuentran más o menos implicados en ello, son tres sus sucesivas funciones cognitivas: interpretar, valorar y retribuir. Esto es a grandes rasgos el papel de un juez cuando, tras construir su propia versión de los hechos, convierte intenciones (un querer decir) en instrucciones (un deber hacer) pues emite un veredicto y otorga premios o sanciones (Casetti F, 1996, pp. 168-169). En algún momento de la vida, todos nos transformamos en jueces, incluso de nosotros mismos. Con mucho mayor motivo lo deben hacer los estudiantes/espectadores del derecho, sobre todo por si alguna vez tienen que decidir algo importante. Para ello no hace falta que en un futuro sean jueces, sino juristas con entusiasmo.

\section{BIBLIOGRAFÍA}

AAVV. (2011): “El comentario de películas”. Guía para clases prácticas. Grado en Derecho, Ed. Dykinson, Madrid, pp. 123-141.

Abel Souto, M. (2013): "Metodologías docentes actuales en Derecho penal y puesta a disposición de recursos de aprendizaje que faciliten el trabajo autónomo", Revista de Derecho, Empresa y sociedad (REDS), n ${ }^{\circ} 3$, pp. 20-39.

Abogacía ESPAÑOLA (n.d): Las mejores películas jurídicas de la historia, https://www.abogacia.es/50-peliculas-juridicas/las-10-peliculas-juridicas-favoritas-de/ (fecha de consulta: 3/09/2019)

Álvarez González, E.M. (2015): "El cine como recurso docente aplicable a la enseñanza del Derecho administrativo”, Revista Jurídica de Investigación e Innovación educativa, REJIE, $\mathrm{n}^{0} 11$, pp.97-109. Artículo en línea. Disponible en http://www.eumed.net/rev/rejie/11/cine.html (fecha de consulta: 03/09/2019).

Casetti, F. (1996): El film y su espectador, Ed. Cátedra, Madrid.

Cordero Cutillas, I. /Escribano Tortajada, P./ Martínez Vázquez de Castro, L. (2014): “Derecho y cine: un nuevo enfoque metodológico para la realización de prácticas”, $V$ 
Jornada sobre docencia del Derecho y tecnologías de la información y la comunicación, UOC, Barcelona, pp. 1-9.

Cordero Cutillas, I. /Escribano Tortajada, P./ Martínez Vázquez de Castro, L. (2013). “Cine y Derecho de Familia: una nueva visión de la metodología práctica”, Revista de Educación y Derecho. Educational and Law Review, $\mathrm{n}^{\circ}$ 9. Artículo en línea. Disponible en http://revistes.ub.edu/index.php/RED/article/view/10209 (fecha de consulta: 03/09/2019).

Cine Y DERECHO (2008): Responsabilidad civil. https://cineyderecho.wordpress.com/category/derecho-civil/responsabilidad-civilderecho-civil/ (fecha de consulta: 3/09/2019)

De Lucas Martín, F.J. (2014): “Sobre Cine, Literatura y Derecho: una aproximación”, Revista de Educación y Derecho, $\mathrm{n}^{0}$ 9. Artículo en línea. Disponible en http://revistes.ub.edu/index.php/RED/article/view/10194 (fecha de consulta: 03/09/2019).

Ferro, C./ Martínez, A.I./ Otero, M. C. (2009):” Ventajas del uso de las TICs en el proceso de enseñanza-aprendizaje desde la óptica de los docentes universitarios españoles”. EDUTEC, Revista Electrónica de Tecnología Educativa. No 29/ Julio 2009. Artículo en línea. Disponible en https://www.edutec.es/revista/index.php/edutece/article/view/451 (fecha de consulta: 12/11/2019)

García Amado, J.A./Paredes Castañón, J.M (coord). (2005): Torturas en el cine, Ed. Tirant lo Blanch, Valencia.

García Manrique, R. (2014): "La mirada de Atticus Finch: Sobre el cine como objeto del saber jurídico”. Revista de Educación y Derecho, n 9, Artículo en línea. Disponible en http://revistes.ub.edu/index.php/RED/article/view/10262 (fecha de consulta 03/09/2019):

Gómez García, J.A. (2010): “Los estudios de Derecho y cine como ámbito de investigación”, Anuario de Derecho de filosofía, pp. 241-246.

Gómez García, J.A. (2009): El derecho a través de los géneros cinematográficos, Ed. Tirant lo Blanch, Valencia.

Holgado Sáez, C. (2013): "El cine como herramienta didáctica para la Historia de Alemania: a propósito del programa de eugenesia en el nacionalsocialismo", Arte y sociedad. Revista de Investigación, $\mathrm{n}^{\circ}$ 4, pp.1-19. Iate. The EU's multilingual term base, en http://iate.europa.eu.

Holgado Sáez, C. (2011): “7 títulos contemporáneos (2001-2011) para la docencia presencial de Derecho penal e Internacional público”, Revista Jurídica de Investigación e Innovación educativa, $\mathrm{n}^{\circ}$ 8, pp-99-116. Artículo en línea. Disponible en http://www.eumed.net/rev/rejie. (fecha de consulta: 03/09/2019).

López Picó, R. (2019): "El cine y la prensa escrita como medios de innovación docente del Derecho procesal”, Revista Jurídica de Investigación e Innovación educativa (REJIE, Nueva Época), $\mathrm{n}^{0}$ 19, pp. 25-38. Artículo en línea, disponible en http://www.revistas.uma.es/index.php/rejienuevaepoca/article/view/5474/5146 (fecha de consulta: 03/09/2019).

Orozco González, M. (2018): "Nuevos horizontes del Derecho de daños: una visión cinematográfica. Materiales para la enseñanza del Derecho de Daños”, en https://digibug.ugr.es/handle/10481/53701.

Ortega Giménez, A., Pérez Tortosa, F. y Pastor Valcárcel, M.C. (2013): Cine y Derecho en 21 películas. Materiales y recursos para el estudio del Derecho a través del Cine, Ed. Editorial Club Universitario, Alicante.

Pérez Montoro, I. (2017): “Cine y Derecho”, en https://www.ui1.es/blog-ui1/universidadisabel-i-derecho-cine (fecha de consulta: 3/09/2019). 
Pérez Triviño, JL. (2010): “Cine y Derecho: aplicaciones docentes”, Anuario de Filosofía del Derecho, $n^{\circ} 26$, Ejemplar dedicado a: XXII Jornadas de la Sociedad Española de Filosofía Jurídica y Política: Viejos temas, nuevos problemas, (Universidad de La Rioja, 26 y 27 de marzo de 2009).

Pérez Triviño, JL. (2007): “Cine y Derecho. Aplicaciones docentes”. Cuadernos de Cine, no 1. Artículo en línea. Disponible en http://www.cervantesvirtual.com/nd/ark:/59851/bmc0c5c4 (fecha de consulta: 3/09/2019).

Pérez Vallejo, AM (2013): "Enseñanza práctica del Derecho civil: replanteamiento metodológico y experiencias de innovación”, Revista de Educación y Derecho. Education and Law review, ${ }^{\circ}$ 8, pp. 1-17.

Presno Linera, M. A (coord.) (2006): Una introducción cinematográfica al Derecho, Ed. Tirant lo Blach, Valencia.

Pujol Balcells, J./ Fons Martín, J.L. (1981): Los métodos de la enseñanza universitaria, Ediciones Navarra, Pamplona.

Ramiro Avilés, M. A. (2014): Derechos, cine, literatura y cómic. Cómo y por qué, Ed. Tirant lo Blach, Valencia.

Rivaya García, B. (2012): Un vademécum judicial. Cine para jueces, Ed. Tirant lo Blanch. Valencia.

Rivaya García, B. (2006): "Derecho y cine. Sobre las posibilidades del cine como instrumento para la didáctica jurídica”, Una Introducción cinematográfica al derecho (coord. Rivaya García), Ed. Tirant lo Blanch, Valencia, pp.12-29

Rivaya García, B./ De Cima, P. (2004): Derecho y cine en 100 películas. Una guía básica, Ed. Tirant lo Blach, Valencia.

Ríos Corbacho, J.M. (2012): “Las consecuencias jurídicas del delito y el cine”, Ciencia Ergo Sum, ${ }^{\circ}$ 19.1, pp. 6-23.

Ruíz Sanz, M. (2014): "Instruir en Derecho y cine: una apuesta entre elecciones y pasiones”, Revista de Educación y Derecho, $\mathrm{n}^{\circ}$ 9. Artículo en línea. Disponible en http://revistes.ub.edu/index.php/RED/article/view/10196/13049 (fecha de consulta: 3/09/2019):

Ruíz Sanz, M. (2010): ¿Es conveniente enseñar derecho a través del cine?, Anuario de filosofía del Derecho, pp. 257-264.

Soto Nieto, F./J. Fernández, F. (2008): Imágenes y justicia: el derecho a través del cine, Ed. La Ley, Madrid.

Salazar Benítez, O. (2015): “La enseñanza del Derecho constitucional a través del cine”, International Journal of Educational Research and Innovation, $\mathrm{n}^{\circ} 4$.

Torres Dulce, E. (2015): El cine carcelario, Ed. Tirant lo Blach, Valencia.

Vaquero Pinto, M.J (2017): "Historia del caso de la talidomina. Dies a quo del plazo de prescripción de la acción de responsabilidad civil. Prescripción y amparo constitucional”, Derecho privado y constitución, $\mathrm{n}^{\circ} 31$, pp. 275-316). http://doi.org/10.18042/cepc/dpc.31.07. 